\title{
TPR/NTRK1 Fusion Protein TRKT2
}

National Cancer Institute

\section{Source}

National Cancer Institute. TPR/NTRK1 Fusion Protein TRKT2. NCI Thesaurus. Code C99861.

A fusion protein (1300 aa, 140 kDa) encoded by the TPR/NT RK1 fusion gene TRK-T2.

This protein is comprised of the $\mathrm{N}$-terminal part of nucleoprotein TPR fused to the Cterminus of the high affinity nerve growth factor receptor protein, including an intact tyrosine kinase domain. 